\title{
Diagnostics and Forecasting of the Turbo-generators Sliding Current Collection Units Technical Condition
}

\author{
Igor Plokhov ${ }^{1, *}$, Igor Savraev ${ }^{1}$, Alexander Ilyin ${ }^{1}$, Oksana Kozyreva ${ }^{1}$, and Sergey Loginov ${ }^{1}$. \\ ${ }^{1}$ Pskov State University, Department of Electric Power, Electric Drive and Automation, 180000 Pskov Lenina 8, Russia
}

\begin{abstract}
The article is about assessing the reliability levels of the main diagnostic procedures, determining prognostic recommendations, developing a three-factor regression expert model, obtaining a generalized assessment of the turbo-generator sliding current collection unit functioning quality, and building a logicalanalytical system for diagnostics and forecasting of the sliding current collection unit technical condition.
\end{abstract}

\section{Introduction}

Sliding current collection units (SCCU) of turbogenerators (TG) technical maintenance (TM) is carried out according a planned preventive principle for which the measuring equipment was almost not used before [1-2]. Therefore, decisions about the maintenance had significant uncertainty.

There is a variety of devices for monitoring of the condition of the SCCU [3]:

1) the device for measuring radio emission during sparking (developed in the USA);

2) the measuring device for overheating of the cooling air (developed by ORGRES and others);

3 ) the measuring device of a voltage drop on the "traverse-ring" section (developed by Ler-turbo and others);

4) the system for detecting brushes with insufficient current load (developed in the former Czechoslovakia);

5) the device for indicating the separation or vibration of brushes (developed by Omsk State Transport University);

6) the control system for current distribution in the brushes (developed by ORGRES) [2];

7) the stand for testing control of the SCCU (developed by "Scientific Research Institute of Electrical Machines") [4];

8) the contactless meter of brush current (developed by the research and production company "Elisa");

9) the device for continuous monitoring of electromagnetic noise of the SCCU [5].

All of the devices have a common disadvantage - they are not able to provide a comprehensive diagnosis and forecasting of the SCCU TG technical condition. This scientific study is devoted to the solution of the problem.

\section{Technical condition control of the SCCU TG}

Functional-semantic and functional networks [3] develop the generalized structural method [4] and have significant advantages among the used models of human-machine systems (HMS). Operations are represented as typical functional units (TFU) and create a model of process in the form of a functional network (FN) [5]. Then calculated assessment of reliability is made [6].

TM is necessary to keep the SCCU in working condition during the TG functioning. The complete functional network of TM of the SCCU was built for the diagnostic process that uses a set of devices [6-10]. The reliability of the diagnostics was calculated using the FN. Using diagnostic devices the diagnostic reliability is $99.96 \%$. The diagnostic reliability without diagnostic devices is $69.1 \%$. The diagnostic reliability of the SCCU TG without devices is only on $19 \%$ higher than the probability of random selection. Improving reliability needs continuously evaluate the technical condition of the SCCU TG and generate control recommendations (CR).

The stationary diagnostic systems was designed: "Iskra", "Obzor", "Relief", "Signal" [6-13], which provide information about the functioning quality of the SCCU TG.

Each of the systems mentioned above is basic to define a quality factor of the SCCU TG. "Obzor" gives the uniformity of the brushes current distribution $Q$, dangerous value is $X_{1}=Q_{\max }=25 \%$. "Iskra" measures the radio-frequency interference and produces the arcing value in points $\left(X_{2}\right)$, the limit value is 2 points. "Relief" system gives three factors: the contact rings beat $\left(x_{1}=\right.$ $\left.\Delta_{\max }=300 \mu \mathrm{m}\right)$, the waiving $\left(x_{2}=\delta_{\max }=200 \mu \mathrm{m}\right)$, the coefficient of relative instability of contact (CRI) $\left(x_{3}=C R I_{\max }=25 \%\right)$. The value limits were obtained using the experimental model of the SCCU TG.

This makes it possible to monitor of the SCCU and generate control recommendations. CR are divided into

* Corresponding author: igor plohov@list.ru 
two classes: current and prognostic. Therefore, the SCCU generalized control logic-analytical system consists of the coordinating and extrapolating parts.

The coordinating part. Stationary diagnostic systems are sources of the evaluation signals, which are processed and provided to the logical-analytical block for generating recommendations (BGR) (Fig. 1).

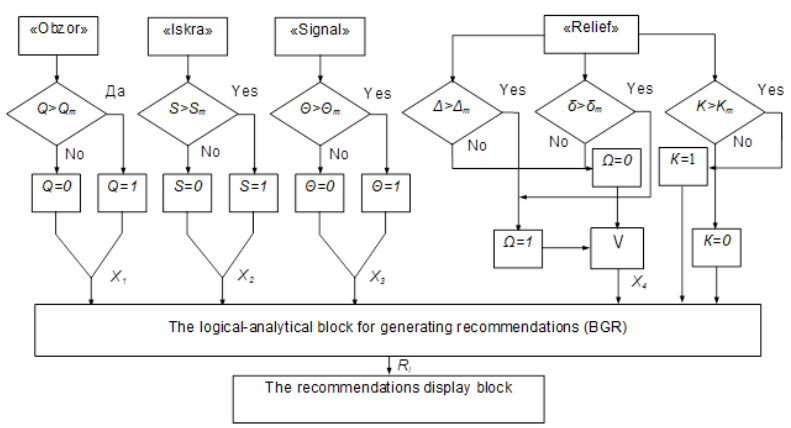

Fig. 1. The coordinating part $(Q-$ quality of current distribution; $S$ - sparking; $\Theta$ - discrepancy of volt-ampere characteristics (VAC); $\Delta, \delta$ - run-out and waviness of slip rings; $K$ - contact relative instability coefficient of the auxiliary brush).

A compliance table, showing the relationship of quality indicators with recommendations, was constructed for definition of the BGR control functions. Considering that the diagnostic system "Relief" has the output indicators $-\Delta, \delta, K$, an additional truth table and a corresponding list of recommendations were built to generate the recommendations.

According to the compliance tables Karnaugh maps were compiled, contour minimization was carried out, and disjunctive normal forms (DNF) of the recommendations as logical functions $R_{1}, \ldots, R_{6}$ were determined (Tables 1 and 2).

Table 1. DNF of the BVR logic-analytical core.

\begin{tabular}{|c|c|}
\hline $\begin{array}{c}\text { Recom } \\
\text { mendati } \\
\text { on }\end{array}$ & Disjunctive normal form of Boolean function \\
\hline$R_{1}$ & $X_{2} \cdot X_{4}$ \\
\hline$R_{2}$ & $X_{2}+X_{1} \cdot X_{4}+X_{3} \cdot \bar{X}_{1}$ \\
\hline$R_{3}$ & $X_{1}$ \\
\hline$R_{4}$ & $X_{2} \cdot \bar{X}_{4} \cdot\left(\bar{X}_{1}+X_{3}\right)$ \\
\hline$R_{5}$ & $X_{4}=\Delta+\delta$ \\
\hline$R_{6}$ & $\bar{X}_{4} \cdot\left[\bar{X}_{1} \cdot\left(X_{2}+X_{3}\right)+X_{2} \cdot X_{3}\right]$ \\
\hline$R_{7}$ & $\bar{\Delta} \cdot \bar{\delta} \cdot K$ \\
\hline$R_{8}$ & $\bar{\Delta} \cdot \delta$ \\
\hline$R_{9}$ & $\Delta \cdot \bar{\delta}$ \\
\hline$R_{10}$ & $\Delta \cdot \delta$ \\
\hline
\end{tabular}

Table 2. Recommendations (formulation)

\begin{tabular}{|c|c|}
\hline $\begin{array}{l}\text { Recom } \\
\text { mendati } \\
\text { on }\end{array}$ & Description \\
\hline$R_{1}$ & Perform machining of slip rings. \\
\hline$R_{2}$ & $\begin{array}{l}\text { Severe contamination of the contact surface of } \\
\text { the ring. Clean the contact surface of the ring. }\end{array}$ \\
\hline$R_{3}$ & $\begin{array}{l}\text { Significant unevenness of the brushes current } \\
\text { distribution. Adjust the pressing forces on the } \\
\text { brushes using devices for measuring brush } \\
\text { currents. }\end{array}$ \\
\hline$R_{4}$ & $\begin{array}{l}\text { Most of the brushes are of poor quality. Discard } \\
\text { brushes for equal resistance with the } 10 \% \\
\text { accuracy. }\end{array}$ \\
\hline$R_{5}$ & Analyze the slip ring profilograms. \\
\hline$R_{6}$ & $\begin{array}{l}\text { The pressing force on the brush is out of the } \\
\text { acceptable range. If } \Theta<-\xi \text { - the pressure is } \\
\text { too strong, else if } \Theta>\xi-\text { the pressure is too } \\
\text { weak. }\end{array}$ \\
\hline$R_{7}$ & $\begin{array}{l}\text { The "Relief" auxiliary brush pressure is too } \\
\text { weak. }\end{array}$ \\
\hline$R_{8}$ & $\begin{array}{l}\text { Increased waviness of the rings working } \\
\text { surfaces. }\end{array}$ \\
\hline$R_{9}$ & $\begin{array}{l}\text { High value of the rings working surfaces } \\
\text { runout. }\end{array}$ \\
\hline$R_{10}$ & $\begin{array}{l}\text { The profilogram is completely unsatisfactory. } \\
\text { Repair and maintenance and must be done. }\end{array}$ \\
\hline
\end{tabular}

The flow diagrams of programs implementing logicalanalytical functions are shown in Fig. 2, 3. The circuit implementation of BGR is also possible.

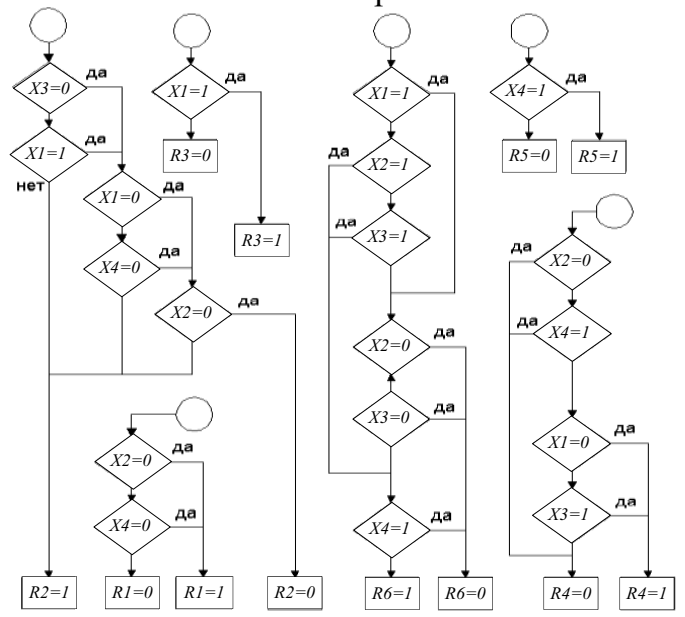

Fig. 2. The flow diagrams of BGR main functions. 


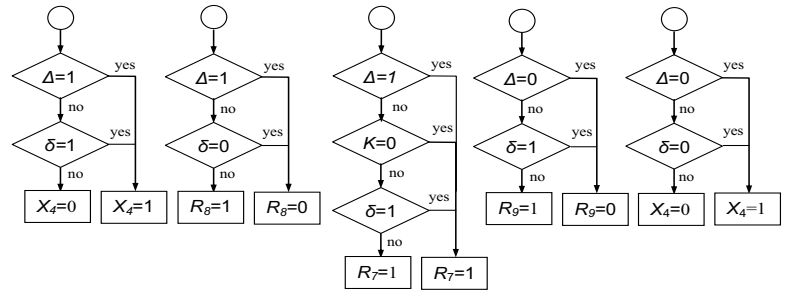

Fig. 3. The flow diagrams of BGR auxiliary functions.

\section{Forecasting of the SCCU TG technical condition}

The forecasting system of the SCCU TG technical condition is designed using the principle of diagnostic signals time approximation with further extrapolation. The forecasting depth is not higher than half of the approximation time. A linear function $Y=a \cdot t+b$ will be used for the quality indicator. The sign and value of the quality indicator determine the forecasting value.

Coefficients of the approximation function are:

$$
\begin{gathered}
a=\frac{\sum_{i=1}^{n} t_{i} \cdot Y_{i}-\frac{1}{n} \cdot \sum_{i=1}^{n} t_{i} \cdot \sum_{i=1}^{n} Y_{i}}{\sum_{i=1}^{n} t_{i}^{2}-\frac{1}{n} \cdot\left(\sum_{i=1}^{n} t_{i}\right)^{2}}, \\
b=\frac{1}{n} \cdot\left(\sum_{i=1}^{n} Y_{i}-a \cdot \sum_{i=1}^{n} t_{i}\right), \cdots \\
=\frac{\left(\sum_{i=1}^{n} t_{i} \cdot Y_{i}-\frac{1}{n} \cdot \sum_{i=1}^{n} t_{i} \cdot \sum_{i=1}^{n} Y_{i}\right)^{2}}{\left[\sum_{i=1}^{n} t_{i}^{2}-\frac{1}{n} \cdot\left(\sum_{i=1}^{n} t_{i}\right)^{2}\right] \cdot\left[\sum_{i=1}^{n} Y_{i}^{2}-\frac{1}{n} \cdot\left(\sum_{i=1}^{n} Y_{i}\right)^{2}\right]},
\end{gathered}
$$
where $t_{i}$ is the $\mathrm{i}$-th timepoint; $Y_{i j}$ is the $\mathrm{j}$-th quality indicator at the $\mathrm{i}$-th timepoint; $r^{2}$ is the correlation coefficient.

The $\mathrm{j}$-th quality indicator $V_{Y j}$ rate is equal to $d Y_{j} / d t=a$. The forecasting characteristic is the time interval within which the $\mathrm{j}$-th indicator does not go out of the acceptable region (RPV). This characteristic will be designated as $T_{n j}$. The forecasting indicators of the technical condition are the quality indicators rates $V_{Y j}$ and the times of the predictive performance $T_{n j}$ according to the approximation formulas.

Consider the options of the $\mathrm{j}$-th quality indicator variation (Fig. 4).

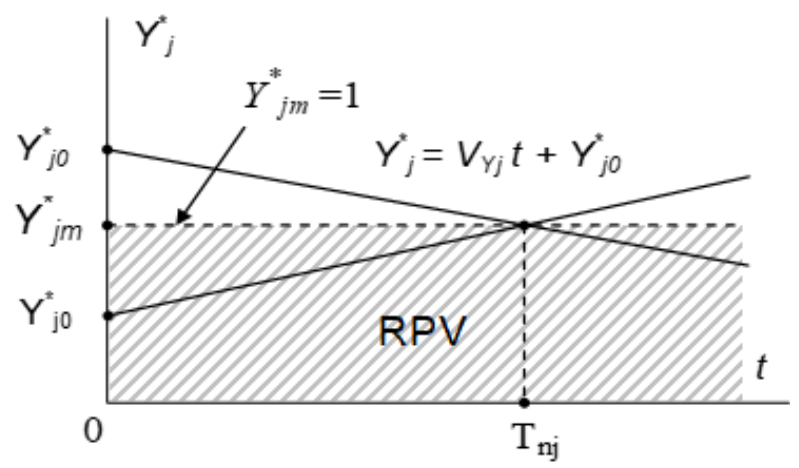

Fig. 4. Dynamics of the quality indicator.

The extrapolating function will be presented in the form

$$
Y_{j}^{*}=a \cdot t+b \text { or } Y_{j}^{*}=V_{Y j} \cdot t+Y_{j 0}^{*},
$$

where the quality indicator rate is:

$$
V_{Y j}=\frac{Y_{j m}^{*}-Y_{j 0}^{*}}{T_{n j}}=\frac{1-Y_{j 0}^{*}}{T_{n j}} \text {, then } T_{n j}=\frac{Y_{j m}^{*}-Y_{j 0}^{*}}{V_{Y j}}=\frac{1-Y_{j 0}^{*}}{V_{Y j}} \text {. }
$$

Thus from knowing the extrapolating function coefficients it is possible to determine forecasting estimates of the quality indicator variation.

The extrapolating function crosses the boundary of the acceptable range in the following cases: $\left(Y_{j m}^{*} \geq\right.$ $\left.Y_{j 0}^{*}\right) \&\left(V_{Y j}>0\right),\left(Y_{j m}^{*}<Y_{j 0}^{*}\right) \&\left(V_{Y j}<0\right)$, and only for them $T_{n j}$ has the final meaning.

To represent the complete set of options for the development of the analyzed processes, a combined replica can be written down (Table 3). The replica contains combinations of two-level and three-level logical variables states, given by the ratios:

$$
\begin{gathered}
Y_{L j}=\left\{\begin{array}{l}
1 \forall Y_{j 0}^{*}>Y_{j m}^{*} \\
0 \forall Y_{j 0}^{*} \leq Y_{j m}^{*}
\end{array},\right. \\
V_{L j}=\left\{\begin{array}{l}
1 \forall V_{j}>0 \\
0 \forall V_{j}=0 . \\
-1 \forall V_{j}<0
\end{array}\right.
\end{gathered}
$$

Table 3. Combined replica of the options for the situation development.

\begin{tabular}{|c|c|c|l|}
\hline$\#$ & $Y_{L j}$ & $V_{L j}$ & \multicolumn{1}{|c|}{ Description } \\
\hline 1 & 0 & -1 & $\begin{array}{l}\text { Indicator decreases in the acceptable } \\
\text { range (improvement). }\end{array}$ \\
\hline 2 & 0 & 0 & $\begin{array}{l}\text { The indicator is constant in the } \\
\text { acceptable range. }\end{array}$ \\
\hline 3 & 0 & +1 & $\begin{array}{l}\text { The indicator increases in the } \\
\text { acceptable range (deterioration). } \\
\text { After the period } T_{n j} \text { the indicator } \\
\text { value will get out of the acceptable } \\
\text { range. }\end{array}$ \\
\hline 4 & 1 & -1 & $\begin{array}{l}\text { The indicator decreases outside of the } \\
\text { acceptable range (improvement in } \\
\text { abnormal mode). After the period } T_{n j} \\
\text { the indicator value will enter into the } \\
\text { acceptable range. }\end{array}$ \\
\hline 6 & 1 & 0 & $\begin{array}{l}\text { The indicator is constant outside the } \\
\text { acceptable range. }\end{array}$ \\
\hline
\end{tabular}

Points 3 and 4 have two options for implementation which differ in the period of reaching the acceptable range boundary (Table 4). This interval can be more or less than the allowed value. 
Table 4. Additional replica of the situation development options.

\begin{tabular}{|c|l|l|}
\hline$\#$ & $\begin{array}{c}\text { Logical } \\
\text { conditions }\end{array}$ & \multicolumn{1}{c|}{ Description } \\
\hline \multirow{3}{*}{3} & $T_{n j}<T_{n j 3}$ & $\begin{array}{l}\text { The indicator will get out the } \\
\text { acceptable range in a very short } \\
\text { period. }\end{array}$ \\
\cline { 2 - 3 } & $T_{n j} \geq T_{n j 3}$ & $\begin{array}{l}\text { The indicator will get out the } \\
\text { acceptable range after a long period. }\end{array}$ \\
\hline \multirow{2}{*}{4} & $T_{n j}<T_{n j 4}$ & $\begin{array}{l}\text { The indicator will enter into the } \\
\text { acceptable in a short period. }\end{array}$ \\
\cline { 2 - 3 } & $T_{n j} \geq T_{n j 4}$ & $\begin{array}{l}\text { The indicator will enter into the } \\
\text { acceptable in a very long period. }\end{array}$ \\
\hline
\end{tabular}

The minimized option of the forecast is shown in the table 5. Using parameters $\Delta, \delta$ and $K$ the generalized estimate for the indicator $Y_{4}$ can be determined.

An expert three-factor model [11] is created and shown in the table 6 . A chosen model is

$$
\hat{z}=b_{0}^{*}+b_{1}^{*} \cdot x_{1}^{*}+b_{2}^{*} \cdot x_{2}^{*}+b_{3}^{*} \cdot x_{3}^{*},
$$

where $\quad z_{\text {avg }}=\frac{1}{m} \cdot \sum_{j=1}^{m} z_{j}$ is the estimation of mathematical expectation; $m=3$ is the number of test implementations; $S_{y i}^{2}=\frac{1}{m-1} \cdot \sum_{j=1}^{m}\left(z_{j}-z_{a v g}\right)^{2}$ is the error mean square of a tests set; $i$ is the experiment; $j$ is the test; $k$ is the factor.

Table 5. Main forecast.

\begin{tabular}{|c|c|c|c|c|c|c|}
\hline Diagnostic system & 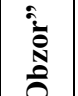 & $\frac{\pi}{\pi}$ & 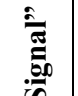 & \multicolumn{3}{|c|}{ "Relief" } \\
\hline Symbol & $Y_{1}$ & $Y_{2}$ & $Y_{3}$ & \multicolumn{3}{|c|}{$Y_{4}$} \\
\hline Indicator & $Q$ & $S$ & $\Theta$ & $\Delta$ & $\delta$ & $K$ \\
\hline \multirow{2}{*}{ Indicator operating value } & $Y_{10}$ & $Y_{20}$ & $Y_{30}$ & \multicolumn{3}{|c|}{$Y_{40}$} \\
\hline & $Q_{0}$ & $S_{0}$ & $\Theta_{0}$ & $\Delta_{0}$ & $\delta_{0}$ & $K_{0}$ \\
\hline Trend & \multicolumn{6}{|c|}{ Increases, decreases or constant } \\
\hline \multirow{2}{*}{ Change rate } & $V_{Y 1}$ & $V_{Y 2}$ & $V_{Y 3}$ & \multicolumn{3}{|c|}{$V_{Y 4}$} \\
\hline & $V_{Q}$ & $V_{S}$ & $V_{\Theta}$ & $V_{\Delta}$ & $V_{\delta}$ & $V_{K}$ \\
\hline \multirow{2}{*}{$\begin{array}{l}\text { Period of reaching the } \\
\text { acceptable range } \\
\text { boundary }\end{array}$} & $T_{Y 1}$ & $T_{Y 2}$ & $T_{Y 3}$ & \multicolumn{3}{|c|}{$T_{Y 4}$} \\
\hline & $T_{Q}$ & $T_{S}$ & $T_{\Theta}$ & $T_{\Delta}$ & $T_{\delta}$ & $T_{K}$ \\
\hline & $T_{Y 1 m}$ & $T_{Y 2 m}$ & $T_{Y 3 m}$ & \multicolumn{3}{|c|}{$T_{Y 4 m}$} \\
\hline
\end{tabular}

\begin{tabular}{|c|c|c|c|c|c|c|c|}
\hline \multicolumn{2}{|c|}{$\begin{array}{l}\text { Allowed period of } \\
\text { reaching the acceptable } \\
\text { range boundary }\end{array}$} & $T_{Q m}$ & $T_{S m}$ & $T_{\Theta \mathrm{m}}$ & $T_{\Delta \mathrm{m}}$ & $T_{\delta m}$ & $T_{K m}$ \\
\hline \multicolumn{2}{|c|}{$\begin{array}{l}\text { Evaluation for each } \\
\text { indicator }\end{array}$} & \multicolumn{6}{|c|}{ Indicator evaluations } \\
\hline \multicolumn{2}{|c|}{ Overall evaluation } & \multicolumn{6}{|c|}{$\begin{array}{l}\text { The quality of the regression } \\
\text { model }\end{array}$} \\
\hline \multirow{3}{*}{$\begin{array}{l}\text { SCCU } \\
\text { maintenance } \\
\text { recommendat } \\
\text { ions }\end{array}$} & Operating & \multirow{3}{*}{\multicolumn{6}{|c|}{ Recommendations (formulations) }} \\
\hline & $\begin{array}{l}\text { after a } \\
\text { period } \\
\Delta \mathrm{t}_{1}\end{array}$ & & & & & & \\
\hline & $\begin{array}{c}\text { after a } \\
\text { period } \\
\Delta \mathrm{t}_{2} \\
\text { after a } \\
\text { period } \\
\Delta \mathrm{t}_{3}\end{array}$ & & & & & & \\
\hline
\end{tabular}

Normalized regression coefficients are:

$$
\begin{gathered}
b_{0}^{*}=\frac{1}{N} \cdot \sum_{k=1}^{N} z_{k}=2.54 ; b_{k}^{*}=\frac{1}{N} \cdot \sum_{i=1}^{k} z_{k} \cdot x_{k i}^{*} ; b_{1}^{*}= \\
0.89 ; b_{2}^{*}=1.1 ; b_{3}^{*}=0.5 .
\end{gathered}
$$

Root mean square error is

$$
S_{b}=\sqrt{S_{y}^{2} / N}=0.091 \text {. }
$$

A generalized quality assessment model was built. The coefficients of the regression model were calculated,

\begin{tabular}{|c|c|c|c|}
\hline \# & $S_{y}^{2}$ & $\begin{array}{l}\varepsilon, \\
\%\end{array}$ & $\begin{array}{c}\text { Statistical indicator (name and } \\
\text { value) }\end{array}$ \\
\hline 1 & 0.16 & 9.25 & $\begin{array}{l}\text { Reproducibility dispersion }\left(S_{y}^{2}=\right. \\
0.53) \text {. }\end{array}$ \\
\hline 2 & 0.26 & 8.8 & $\begin{array}{l}\text { Number of degree of freedom } S_{y}^{2} \\
\left(f_{y}=32\right) .\end{array}$ \\
\hline 3 & 2.47 & 8.7 & Root mean square error $\left(S_{b}=0.18\right)$. \\
\hline 4 & 1.19 & 9.6 & $\begin{array}{l}\text { Significance level of criteria }(\alpha= \\
0.05)\end{array}$ \\
\hline 5 & 3.4 & 9.5 & Quantile table value $(t=2.04)$. \\
\hline 6 & 2.15 & 9.75 & Confidence $\operatorname{span}(\Delta b=0.37)$ \\
\hline 7 & 2 & 6.9 & $\begin{array}{l}\text { Number of degree of freedom }\left(S_{a d}=\right. \\
11) .\end{array}$ \\
\hline 8 & 0.71 & 7.8 & Calculated value of the Fisher \\
\hline 9 & 3.9 & 9.4 & Fisher's test table value $\left(F_{t}=2.56\right)$. \\
\hline 10 & 2.6 & 9.8 & $F_{p}<F_{t}$, therefore the model is \\
\hline 11 & 2.47 & 8 & \\
\hline
\end{tabular}
the analysis of significance and adequacy was carried out. The results are presented in the table 6 .

Table 6. Parameters of the generalized model. 


\begin{tabular}{|c|c|c|c|}
\hline 12 & 1.2 & 9.08 & \multirow{5}{*}{$\begin{array}{c}\text { The model normalized coefficients: } \\
b_{0}^{*}=2.31 ; b_{1}^{*}=0.64 ; b_{2}^{*}=0.72 ; \\
b_{3}^{*}=0.24 ; b_{4}^{*}=0.44 \\
\text { Coefficient } b_{3}^{*} \text { is insignificant, } \\
\text { because of } b_{3}^{*}<\Delta b \\
\text { The model natural coefficients: } \\
b_{0}=0.27 ; b_{1}=0.26 ; b_{2}=0.29 \\
b_{3}=0.096 ; b_{4}=0.18\end{array}$} \\
\hline 13 & 3.4 & 9.17 & \\
\hline 14 & 2.14 & 8.9 & \\
\hline 15 & 2 & 7.75 & \\
\hline 16 & 0.71 & 8.17 & \\
\hline
\end{tabular}

The model in natural form is

$$
\begin{gathered}
\hat{Z}=0.28+0.26 \cdot X_{1}+0.29 \cdot X_{2}+0.064 \cdot x_{1}+ \\
0.079 \cdot x_{2}+0.036 \cdot x_{3} .
\end{gathered}
$$

According to the Minenergo order \#192 (17th March 2020) "About changes into the methodology of the technical condition assessment of the general technological equipment and power lines of the electrical plants and electrical power system, passed by the order \#276 of Minenergo (26th July 2017)" the technical condition quality index (TCI) of the SCCU TG is defined by the scale $0-4$, where 0 is the critical index and value calculated as ratio of the actual to regulatory value.

To take TCI from the regression model (4) next transformations will be made. After substitution of the value limits in the regression model (4) the maximum value of the general quality factor is

$$
\begin{gathered}
\hat{Z}=0.28+0.26 \cdot X_{1}+0.29 \cdot X_{2}+0.064 \cdot x_{1}+ \\
0.079 \cdot x_{2}+0.036 \cdot x_{3}=42.98 .
\end{gathered}
$$

Thus, taking into account the offset -1 and the maximum for $T C I=4$, the regression factor 42.98 , the technical condition index of the SCCU TG is

$$
T C I=4 \cdot(1-\hat{Z}) / 42.98=(1-\hat{Z}) / 10.745 \text {. }
$$

For example, when the SCCU works well the diagnostic factors: the current distribution quality is 10 , the arcing level is 1 points, the ring beat is 120 , the waving is 100, CRI is 10 , then TCI will be 2.25 . When all factors equal zero CRI will be 4 , what is the best value. When the factors are critical, then TCI will be 0 , what is the worst case.

The generalized quality assessments being found with the models are used in the technical maintenance of the SCCU TG combined with the forecast generation system.

\section{Conclusion}

Thus, the article considers the control logic-analytical system that allows developing the operating and forecasting control recommendations for the maintenance based on the generalized estimates of the four quality indicators of the SCCU TG functioning.

The method, algorithms and design of stationary fourfactor diagnostics and forecasting of the SCCU TG technical state increase the operational reliability of the brush-contact device and the turbo-generator. The factors are the current distribution quality indicators, the dynamic profile of the contact surface, the sparking level and the volt-ampere characteristics deviation, determined by the continuous diagnostic systems.
Tasks to be done: 1) development of individual forecasting functions of the logic-analytical system; 2) implementation of the system at power plants for power turbine generators; 3) publication of the obtained scientific results in international journals.

\section{References}

1. Brush-contact apparatus of turbogenerators TVV and TVF, Maintenance instruction OBS.460.469.IE, AO “Electrosila”, 26 (1978) (in Russian)

2. Typical instruction on maintenance of contact rings set and brush apparatus of turbogenerators of power $165 \mathrm{MW}$ and more, TI 34-70-024-84, 36 (1984) (in Russian)

3. Yu.Ya. Mezhennyi, E.P. Osadchiy G.S. Bronstein, Energetic, Control system of brush-contact apparatus of turbogenerator, 5 (1994) (in Russian)

4. V.B. Berezhanskiy, V.A. Pikulsjiy, Yu.L. Presnov, El. Stations, Design and integration of new means of technical condition assessment in Lenenergo, 3 (1994) (in Russian)

5. L.I. Braude, V.V Maslov, Design and integration of new alternative methods of turb- and hydrogenerators control, High frequency control methods control of stators and brush-contact devices of generators (1996) (in Russian)

6. G.I. Ankudinov, Synthesis of complex objects structure (Logic-combinatorial approach) (1986) (in Russian)

7. A.I. Gubinskiy, Reliability and quality of ergatic systems functioning (1982) (in Russian)

8. A.N. Adamenko, A.T. Asherov, I.L. Berdnikov, Information-control man-machine systems: research, design, testing, reference guide (1993) (in Russian)

9. I.V. Plokhov, I.E. Savraev, Ya.A. Rodionov, Electrotechnic, Quality assessment of brush device of electric machines using diagnostic complex "Diakor", 3, 16-19 (1995) (in Russian)

10. I.V. Plokhov, I.E. Savraev, A.V. Andrusich, Elektrosila, Diagnostic system for current collection units of turbogenerators, 40, 171-176 (2001) (in Russian)

11. I. Plokhov, I. Savraev, A. Markov, A. Ilyin, O.Kozyreva, N. Kotkov, Environment. Technology. Resources, Industrial tests of current distribution dynamics in the brush-contact apparatus of the turbo-generator, 3, 258-268 (2017)

12. I.V. Plokhov, V.E. Egorov, V.I. Harchenko, Device for measuring of a brush contact relative instability coefficient of brush-collector unit of an electric machine, Invention description \#1702465 (1991) (in Russian)

13. I.V. Plokhov, I.E. Savraev, A.V. Andrusich, Elektrosila, Approach of current distribution control of current unit brushes of an electric machine and device for the purpose, Invention description \#2178609 (2002) (in Russian) 